Rev. Elev. Méd. vét. Pays trop., 1974, 27 (2) : 145-161

\title{
Prophylaxie et vaccination dans la péripneumonie bovine Évolution des techniques et applications pratiques actuelles
}

\author{
par A. PROVOST $\left(^{*}\right)$
}

a Rien n'est jamais perdu tant qu'il reste quelque chose d trouver.

Pierre Dac, «Les pensées».

\begin{abstract}
RESUME
Après avoir montré qu'à l'heure actuelle la prophylaxie médicale de la péripneumonie est la seule méthode de lutte pragmatiquement valable en Afrique et indiqué les facteurs limitant l'activité des vaccins antipéripneumoniques, l'auteur passe en revue les différents immunigènes préconisés. Il conclut qu'en l'absence de vaccin idéal, reflétant en fait notre méconnaissance de l'immunité dans la maladie, la vaccination doit s'appuyer sur la souche $\mathbf{T}_{1}$, ou éventuellement sur la souche $\mathrm{KH}_{s} \mathrm{~J}$, pour la prophylaxie de masse, et sur la souche $T_{2}$ pour l'intervention dans les foyers.
\end{abstract}

\section{INTRODUCTION : PROPHYLAXIE SANITAIRE OU PROPHYLAXIE MEDICALE?}

L'éradication de la péripneumonie d'un territoire est théoriquement très simple et se base sur trois caractéristiques épizootiologiques de la maladie:

- la péripneumonie ne touche que les bovins domestiques;

- elle est peu contagieuse, la contagion directe prévalant sur tout transfert indirect du contage; pour se réaliser, elle requiert un contact étroit, répété et prolongé;

(w) I.E.M.V.T., Laboratoire de Farcha, B.P. 433 N'Djamena, République du Tchad.
- elle n'est pas toujours mortelle mais, parmi les animaux apparemment guéris qui survivent, existe une certaine proportion de porteurs chroniques de lésions pulmonaires encapsulées s'ouvrant parfois dans une bronche; ces porteurs chroniques assurent la pérennité et la dissémination de l'infection;

De là découle une règle d'or de police sanitaire qui est, en complément de la quarantaine, l'abattage des malades et des contaminés. Des modalités particulières à tel ou tel pays ont pu être édictées, l'abattage a pu être immédiat ou légèrement différé, avec ou sans indemnisation des propriétaires, mais il n'est pas d'exemple que le succès n'ait pas suivi, là où cette méthode draconienne a pu être appliquée avec rigueur et sans failles. 
En sont témoins, l'assainissement des EtatsUnis à la fin du siècle dernier; de l'Europe au début de ce siècle; du Japon; de l'Afrique du Sud et plus récemment des états méridionaux de l'Australie. Le récent foyer de l'état de Victoria (1965) est un bon exemple de l'efficacité de cette politique, tout comme vient encore de le montrer l'extinction en quelques semaines du foyer pyrénéen français en 1967.

Au passif de l'abattage, on peut invoquer le coût élevé immédiat de l'opération, nécessitant de surcroît une coopération totale des propriétaires.

Il semble que ces deux seules restrictions hypothèquent son application dans les pays nouvellement indépendants d'Afrique.

Certains d'entre eux pourtant, en particulier le Nigéria du Nord, se sont efforcés de mettre sur pied une telle pratique d'abattage des malades et contaminés, assortie de la propagande nécessaire; le succès était en bonne voie quand sont survenus des troubles politiques qui ont tout remis en question. Ailleurs, si la législation sanitaire prescrit bien l'abattage, on s'aperçoit qu'en pratique sa mise en œuvre se heurte à d'énormes difficultés. Au nombre de celles-ci on peut citer :

a) L'opposition farouche des propriétaires, même lorsque l'indemnisation est largement calculée ou que le remplacement du bétail est proposé. Pour eux, en effet, la perte du troupeau équivaudrait à la ruine du prestige social, à un authentique crève-cœur (les bovins faisant partie intégrante de la famille), quand ce ne serait pas à la famine; tel est le cas des Masaïs de l'Est Africain ou des Bororos d'Afrique centrale ou occidentale, dont l'unique source de protéines est la viande, le sang ou le lait de leurs vaches. Il faut également avoir à l'esprit des cas toujours délicats, comme ceux de nombreux petits agriculteurs des zones arachidières ou cotonnières d'Afrique tropicale, investissant leurs économies dans l'achat d'un bouf qui servira à labourer leur champ, aux fêtes rituelles ou au paiement d'une dot.

C'est alors un aphorisme que de dire que, là où existe encore la péripneumonie, l'individualisme l'emporte sur l'intérêt général. Aux yeux de la logique occidentale, on peut certes parler d'indiscipline et soutenir que la notion de bien collectif est encore loin d'avoir pénétré en Afrique intertropicale. Cette attitude des populations s'y justifie pourtant par le souvenir de la lutte ancestrale contre les conditions géographiques ou météorologiques adverses, que seuls les progrès de l'éducation et de la technique, et l'apparition d'une nouvelle structure sociale, pourront graduellement effacer.

b) Les interdits religieux, excluant la mise à mort des animaux, comme en Assam.

c) Le coût élevé de l'opération pour de jeunes Etats à équilibre économique et financier encore instable.

II n'est, d'autre part, pas douteux que des répercussions politiques, pouvant aller jusqu'à la rébellion ou le départ massif de la population, seraient déclenchées par l'abattage généralisé de troupeaux contaminés. Il semble aussi prouvé que l'imposition des éleveurs selon les têtes de bétail (pratique dictée par la nécessité) n'est pas en faveur d'une authentique déclaration de la totalité du cheptel et tend à laisser dans l'ombre, pour les autorités administratives et sanitaires, un certain nombre de bovins parmi lesquels peuvent exister des malades.

C'est alors un autre aphorisme que d'affirmer que la pérennité de la péripneumonie est contemporaine d'un paupérisme individuel et d'un paupérisme d'Etat.

d) La précarité actuelle de l'encadrement vétérinaire, indispensable pourtant pour établir le diagnostic clinique ou expérimental de l'infection, pour apprécier la valeur sur pied des bovins devant être abattus et assurer en général la surveillance technique et financière des opérations.

On remarquera que les raisons qui viennent d'être invoquées tiennent plus à la structure socio-économique actuelle des territoires où règne encore l'enzootie péripneumonique, qu'à de véritables difficultés technologiques. Il n'est donc pas déraisonnable de penser que, le progrès aidant, l'on puisse arriver dans l'avenir à $\mathrm{y}$ imposer des mesures sanitaires qui ont fait leurs preuves ailleurs.

Dans un premier temps, la lutte contre la péripneumonie ne peut et ne poùrra faire appel qu'à la vaccination assortie de mesures sanitaires mineures, comme par exemple l'isolement des malades (78). Seront totalement exclues 
toutes tentatives des traitements par quelque médicament ou antibiotique que ce soit; ceuxci entraînent le fallacieux espoir d'un retour à la santé, mais aucun traitement connu ne peut assurer la guérison bactériologique des porteurs chroniques.

Un tel programme se basant sur la vaccination doit-il être envisagé ? La réponse est affirmative si l'on veut réduire l'importance de la péripneumonie dans ces régions du globe qui ont à la fois une forte demande en protéines animales et un potentiel certain en fournitures de viande. Ce faisant, on gardera présent à l'esprit que le succès est dépendant à la fois des moyens et des méthodes mis en cuvre, facteurs qui seront évoqués dans les paragraphes suivants. On se gardera d'affirmer pouvoir atteindre l'éradication totale (encore que, comme on le verra, des opérations bien conduites permettent d'y arriver) mais plutôt un taux d'infection si bas que, le temps venu, on puisse alors mettre en place la police sanitaire rigide qui conduira à la disparition de la maladie.

Des exemples heureux de cette politique existent. Ce sont les cas du Barotseland en Afrique du Sud et plus récemment du Queensland et de l'Australie du Nord où la vaccination généralisée a été l'arme la plus importante pour venir à bout d'une infection péripneumonique implantée depuis un siècle (7).

\section{LES VACCINS ANTIPERIPNEUMONIQUES}

Exposer les problèmes de la vaccination contre la péripneumonie pourrait revenir à faire un historique des méthodes employées : si elles sont nombreuses, c'est qu'aucune n'a donné entièrement satisfaction.

On pourrait également les décrire selon les laboratoires producteurs ou par école de pensée, tellement les solutions adoptées sont variables d'un pays à un autre. Pour obtenir une bonne revue générale permettant des comparaisons fructueuses, il a paru préférable de classer vaccins et procédés de vaccination par "type ». Cette méthode d'exposition a l'avantage de permettre une appréciation objective et d'insister sur ceux dont l'utilisation actuelle est la plus large.

\section{BASES GENERALES DE LA VACCINATION ANTIPERIPNEUMONIQUE}

1. La vaccination se heurte à plusieurs difficultés :

- d'ordre scientifique : en raison de la méconnaissance de la nature de l'immunité, en particulier de l'ignorance du type d'anticorpssupport immunitaire et du ou des antigènes des mycoplasmes générateurs de la résistance spécifique, qui serviraient de base pour le choix et l'amélioration des vaccins;

- d'ordre technique : en raison du manque de souplesse dans le maniement des cultures de $M$. mycoides au laboratoire et de l'incertitude du contrôle d'efficacité vaccinale par épreuve virulente;

- d'ordre étiologique: puisque des différences de réceptivité des bovins à vacciner, variables à l'infini, mettent en cause l'espèce (bœuf et zébu), la race, le groupe d'individus, l'individu isolé, la région considérée, le mode d'élevage; la vaccination constitue d'ailleurs un révélateur de la réceptivité bien supérieur à l'infection spontanée;

- d'ordre épidémiologique : puisque lors d'une campagne de prophylaxie la vaccination risque d'intervenir aussi bien sur des sujets neufs que sur des animaux en incubation, sur des porteurs de séquestres que sur des sujets guéris ou infectés par des mycoplasmes saprophytes.

2. Il importe de souligner surtout la difficulté d'appréciation de l'épreuve virulente postvaccinale dans les contrôles d'activité des vaccins.

Les quatre méthodes d'épreuve successivement employées se révèlent, en effet, toutes critiquables :

- Linoculation hypodermique d'une souche pathogène de $M$. mycoides révèle une immunité contre la seule réaction willemsienne, fort différente de la maladie pulmonaire. Par ailleurs, elle est diversement appréciée selon sa nature «tout ou rien * ou selon son degré «plus ou moins». En principe, toutefois, depuis la réunion de Muguga, en 1964, c'est la première lecture qui doit intervenir, de 8 à 42 jours après l'inoculation d'épreuve, avec essai de réisolement du mycoplasme opéré sur les réactions douteuses (76); 
- la reproduction de la maladie par aérosols virulents a été abandonnée en Australie après 20 ans d'exploitation, en raison d'erreurs imprévisibles (5);

-. L'embolisation virulente de culture pathogène par voie intraveineuse préconisée par DAUBNEY, et METTAM et FORD, est aussi tombée en désuétude pour des motifs semblables $(12,51)$;

- La contamination provoquée par des malades créés par intubation endobronchique est actuellement la seule utilisée; elle reproduit certes les conditions spontanées de la contagion, mais elle est fort longue (34).

Enfin, les critères d'activité varient encore selon le degré de protection recherché, à l'image de la vaccination antibrucellique :

- soit la protection clinique seulement, exigence minimale;

- soit, en outre, la stabilisation sérologique à l'épreuve, le titre en fixation du complément ne devant alors subir aucune augmentation;

- soit enfin, la protection totale de l'infection, exigence maximale, avec vérification de la non-infection des ganglions après abattage des sujets vaccinés puis éprouvés par contamination.

3. Règles générales. Les vaccins destinés à lutter contre la maladie doivent obéir à trois règles impératives, s'accordant respectivement avec la nature présumée de l'immunité.

\section{a) Vitalité}

La vitalité du germe vaccinal doit être respectée, car seuls les vaccins à mycoplasme spécifique vivant se révèlent d'efficaces immunigènes, déterminant peut-être une immunité de prémunition, puisque le mycoplasme ou ses antigènes sont retrouvés jusqu'au $7^{\mathrm{e}}$ mois après la vaccination $(48,49)$.

Dès lors s'excluent ou sont tombés en désuétude :

- Les vaccins homologues inactivés préparés à partir de produits pathologiques ou de cultures :

- vaccin de CURASSON et HANRAS (1930), à base de « lymphe » pulmonaire citratée et formolée à 4 p. 1000 , utilisé aux doses de 40 à $75 \mathrm{ml}$, voire $120 \mathrm{ml}$ par voie souscutanée (9);
- vaccin de WALKER (1930), utilisant les tissus de la réaction willemsienne, pulpés et formolés à 1 p. 100 (84);

- vaccin de POTAROFF (1934), comprenant de la « lymphe \& diluée à 50 p. 100 dans l'eau et additionnée de formol à 0,5 p. 100 , à la dose de 2 à $4 \mathrm{ml}$ par voie sous-cutanée (62);

— vaccin de GIRARD (1942), additionnant $5 \mathrm{~g}$ de lanoline à 2 ou $4 \mathrm{ml}$ de «lymphe *, puis après séjour de $48 \mathrm{~h}$ à $25^{\circ} \mathrm{C}$, de l'huile de foie de morue qsq $20 \mathrm{ml}$, utilisable à la dose de $2 \mathrm{ml}$ par voie sous-cutanée (25);

- vaccin de PRIESTLEY (1961), avec de la "lymphe" thermo-inactivée à $56^{\circ} \mathrm{C}(65)$ et celui de SHIFRINE et BEECH (81) fait d'une culture de 2 jours, inactivée ensuite 30 minutes à $56^{\circ} \mathrm{C}$ puis adjuvée;

- vaccin de BROWN (1966), avec de la "lymphe » inactivée par la bêta-propiolactone à 1 p. 100 pendant 2 jours à $4^{\circ} \mathrm{C}$, additionnée au $1 / 4$ d'hydroxyde d'aluminium et utilisée par voie sous-cutanée à la dose de $10 \mathrm{ml}$ à trois reprises à 10 jours d'intervalle (2);

- vaccin de HALL (1930), de culture de 30 jours, formolée à 0,2 p. 100 (27);

- vaccin de GRYAZIN et SHCHERBAKOV (1954), de culture formolée avec deux revaccinations à 15 jours d'intervalle (26);

- vaccin de MENDES (1957), en Angola, utilisant des cultures de 6 jours, formolées à 0,3 p. 100 , additionnées de 10 p. 100 d'hydroxyde d'aluminium préparé selon la technique de CALLOW, à la dose de $10 \mathrm{ml}$ par voie sous-cutanée (50);

- vaccin de TURNER (1960), de culture concentrée 50 fois par centrifugation, inactivée par formol à 0,4 p. 100 à la dose de $1 \mathrm{ml}$ par voie sous-cutanée (76);

- vaccin saponiné de PROVOST (1963) à base de lysats de culture par la saponine (70);

- vaccin expérimental lysé et adjuvé de PROVOST (1964-66) additionné d'adjuvant de FREUND, à la dose de $2 \mathrm{ml}$ dans le fanon (67).

- Les vaccins hétérologues, utilisant:

- la souche YG isolée d'une péritonite caprine, essayée en Australie (1963-64), comme vaccin de culture (8);

- diverses souches mycoplasmatiques : $M$. agalactiae par BRIDE et DONATIEN (1925), $M$. laidlawi et la souche Tu de $M$. gallinarum 
par PROVOST et collab. (1964) avec le même insuccès, et aussi le B.C.G., destiné à renforcer les défenses naturelles (73).

Tous ces essais ont conduit à la déception, bien que certains résultats aient pu dériver de l'utilisation des vaccins de GIRARD, de BROWN, de MENDES et de TURNER, grâce à l'obtention d'une immunité partielle, quelquefois prolongée sur plusieurs mois. Quant au lysat-vaccin expérimental de PROVOST (47, 73), inapplicable en raison de son prix de revient élevé. il comporte l'enseignement de la possibilité de l'acquisition d'une immunité élevée et prolongée sur 15 mois par des endoimmunigènes en très fortes quantités; l'argument est de valeur sous l'angle pathogénique.

\section{b) Virulence résiduelle}

La virulence résiduelle des souches vaccinales s'échelonne selon des degrés très étendus, allant de l'avirulence complète à la virulence intégrale, pour autant que le contrôle de la virulence sur bovins puisse être extrapolé à l'ensemble des résultats obtenus, en raison de l'hétérogénéité de la réceptivité raciale, voire individuelle. Dès lors, interviendront des conditions très variables de l'application vaccinale : selon l'espèce bénéficiaire, les taurins se révélant plus sensibles que les zébus; selon l'âge, qui doit en général excéder 6 ou 8 mois, afin d'éviter les lésions articulaires et cardiaques du jeune; selon la terroir considéré et aussi selon le but poursuivi (nivellement de la réceptivité collective à un niveau moyen ou protection totale et durable).

C'est l'intrication de tous ces facteurs qui, dans le passé mais aussi de nos jours, fait chanter les louanges de tel ou tel vaccin alors qu'il est accusé ailleurs de créer des lésions postvaccinales qui en rendent l'application rédhibitoire.

\section{c) Voie d'injection}

La voie d'injection doit généralement respecter la règle de la zone vaccinale «permise *, à conjonctif dense et peu réactionnel, afín de limiter les suites locales et générales fâcheuses, voire mortelles. Pendant longtemps, on a préconisé la vaccination caudale, toujours en vogue en nombre de pays, pour respecter cette règle avec des vaccins à virulence résiduelle non négligeable. Pour des raisons de commodité, la tendance actuelle s'oriente vers l'utilisation préférentielle de la voie sous-cutanée rétroscapulaire avec, en corollaire, l'emploi de vaccins à virulence résiduelle acceptable ou, mieux, abolie.

\section{FORMULES VACCINALES}

Elles distinguent les divers degrés de virulence de la souche vaccinale.

\section{Souches virulentes intégrales}

- La méthode willemsienne originelle ne semble plus employée, avec toute sa technologie extrêmement riche concernant la récolte du matériel vaccinal (lymphe pulmonaire ou de réaction willemsienne), son traitement et ses divers modes d'inoculation. Mais ce n'est que récemment que l'utilisation des « sétons virulents », c'est-à-dire des fils de laine imprégnés de «lymphe » virulente puis desséchés à l'ombre, a été abandonnée par les propriétaires australiens du Queensland.

- Il semblerait, en revanche, que la vieille méthode traditionnelle africaine d'inoculation d'une macération de poumons péripneumoniques soit toujours en faveur auprès de quelques populations, particulièrement en Nigéria du Nord, au Niger et en Somalie. Au Tchad, on rencontre encore, de temps à autre, sur les marchés, des bovins adultes qui présentent des exostoses nasales. Le mode opératoire consiste dans la récolte de la «lymphe » ou dans la préparation d'une macération de poumon, avec du lait ou de l'urine, puis dans l'incision de la peau du chanfrein. La réaction locale est violente (photo $\mathrm{n}^{\circ} 1$ ), pouvant conduire à la création d'exostoses nasales qui en ont imposé pour la description d'une nouvelle race bovine au siècle dernier (Bos triceros senegalensis, photo $\mathrm{n}^{\circ}$ 2) (79). La mortalité post vaccinale reste importante.

- Les cultures pathogènes, remplaçant, au début du siècle, la "lymphe ", sont tombées partout en désuétude.

\section{Souches de virulence moyenne}

Les observations de DUJARDIN-BEAUMETZ en 1900, suivies de celles de WALKER au Kenya en 1921 (83), puis de BENNETT 


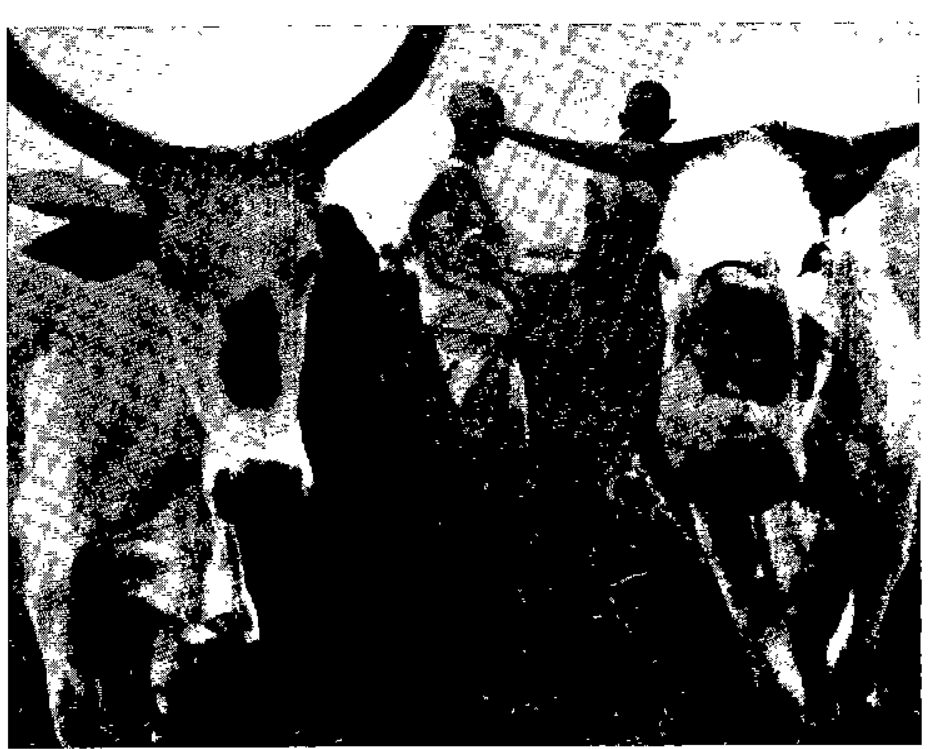

Photo 1. - Réactions nécrotiques.

Ces réactions s'observaient il y a encore très peu de temps dans certains troupeaux de zébus d'Afrique vaccinés sur le chanfrein avec de la lymphe pleinement virulente; le procédé n'est plus guère utilisé.

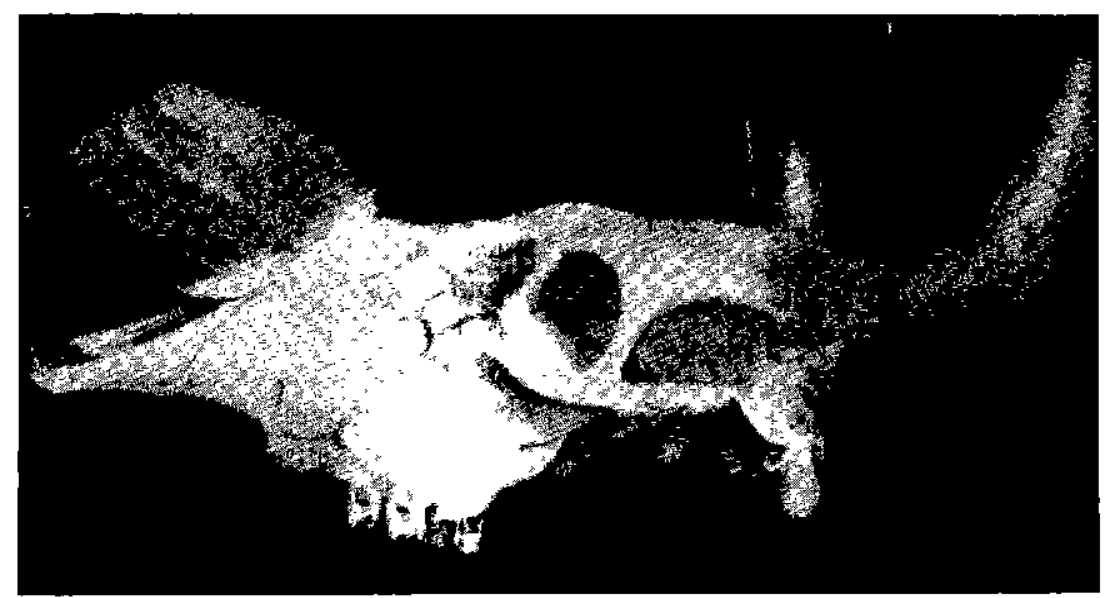

Photo 2. - Réaction postvaccinale d'exostose.

Réaction osseuse avec étui corné observée sur une tête de zébu vacciné sur le chanfrein avec du tissu pulmonaire péripneumonique virulent, selon le procédé indigène des Maures. Elle correspond au Bos triceros décrit en Afrique (79).

au Soudan (1), amenèrent la conclusion que les repiquages en bouillon suscitaient une certaine dégradation du pouvoir pathogène de $M$. mycoides : pour une souche donnée, un certain nombre de repiquages in vitro entraîne l'obtention d'une culture «atténuée ». L'atténuation est caractérisée par l'apparition d'incidents mineurs, en général un cedème régressant spontanément, à la suite de l'introduction sous-cutanée ou intradermique du germe dans le tou- pillon de la queue. Il ne s'agit nullement d'une atténuation fixée, car la poursuite des repiquages en série accentue cette hypovirulence, en même temps, semble-t-il, que disparaissent les propriétés immunigènes. Le concept de base consiste donc dans un compromis délicat entre la conservation d'un pouvoir immunigène encore suffisant et les réactions locales déjà acceptables. Les moyens d'obtention ont été fort variés. 


\section{a) Sélection de souche d virulence naturelle modérée}

La plus fameuse, la souche australienne $V_{5}$, fut préconisée dès 1935 par CAMPBELL (6). Isolée d'un cas clinique, elle ne montra, dès l'origine, qu'un pouvoir pathogène réduit. Le nombre de repiquages est limité encore actuellement à une vingtaine seulement, pour ne pas entraîner une trop profonde dégradation de l'immunogénèse, qui est préservée par la constitution d'une «banque » conservée en neige carbonique.

La préparation de ce vaccin, au C.S.I.R.O. de Parkville, est parfaitement codifiée. La culture est réalisée en bouillon BVF-OS, réparti directement en flacons de $8 \mathrm{oz}$, qui sont ensemencés avec la souche. Après 3 jours de culture, le vaccin est contrôlé, puis envoyé sans précautions spéciales aux utilisateurs. Sa conservation est satisfaisante pendant 3 mois, sous réserve que la température ne dépasse pas $45^{\circ} \mathrm{C}$, et qu'il ne soit pas exposé à l'insolation directe (32).

L'inoculation s'effectue dans le tissu conjonctif du toupillon de la queue, à la dose de $0,2 \mathrm{ml}$. Elle entraîne une mycoplasménie précoce et transitoire, quelques heures après l'intervention.

En une dizaine de jours, une réaction locale se manifeste sous forme d'une tuméfaction œdémateuse de l'extrémité caudale, sur une dizaine de centimètres, laissant exsuder un peu de sérosité; elle s'efface, dans la règle, en deux semaines. Néanmoins, sur 1 p. 100 environ des vaccinés, tout spécialement chez le bétail laitier, l'œdème réactionnel peut remonter au long de la queue, envahir la région fessière, puis le périnée, conduisant à la mort $0,20 \mathrm{p}$. 100 environ des sujets. Redoutable il y a encore quelques années, cette éventualité est désormais justiciable d'un traitement aux tétracyclines ou à la spiramycine $(28,45)$. Des complications de myocardite peuvent aussi se manifester chez les veaux, qu'il n'est pas recommandé de vacciner avant l'âge de 3 mois.

La vaccination est suivie d'une montée fugace d'anticorps agglutinants et fixant le complément, puisque, 45 à 60 jours après la vaccination, le comportement sérologique de la plupart des bovins vaccinés est redevenu normal.
L'immunité s'installe en une dizaine de jours et paraît encore suffisante après plusieurs années. En Australie, l'emploi sur une très large échelle, de millions de doses de la souche $V_{5}$ a conduit à la situation actuelle favorable, puisque l'éradication totale de la maladie a été réalisée en 1972 (7).

\section{b) Atténuation artificielle «in vitro» d'une souche primitivement pathogène}

C'est à ce type de vaccin qu'un abus de langage décerne le nom de «vaccin BENNETT ». A vrai dire, si WALKER (83), puis BENNETT (1) furent bien les initiateurs de la méthode d'atténuation in vitro, de multiples variantes, propres à chaque laboratoire de production et non codifiées, ont été proposées dans le dessein de respecter tant les conditions locales de production que les différences de réceptivité du bétail bénéficiaire.

- Les souches d'origine sauvage furent naguère les seules utilisées avant l'introduction de la lyophilisation, vieille de 20 ans environ, afin d'éviter la dégradation immunogénique déterminée par les repiquages in vitro. Aujourd'hui, en dépit de la cryodessiccation, les souches n'en demeurent pas moins fort diverses : soit isolées directement de "lymphe , comme la souche $\& F \otimes$, relativement virulente du Soudan (11); soit, comme la souche locale d'Assam, atténuées dès la $12^{\mathrm{e}}$ subculture; soit après plus de 100 repiquages, pour une souche espagnole. D'autres encore ont, au préalable, subi une série de passages par ovoculture en cuf embryonné, matériel aisément lyophilisable : telles, la souche $T_{1}$ de l'Est africain parvenue à son $44^{\mathrm{e}}$ passage dans l'œuf (80), la souche $T_{2}$ utilisée par le laboratoire de Farcha ou les souches du laboratoire de Dakar, au $20^{e}$ passage pour la souche $T_{3}$, elle aussi d'origine est-africaine, ou au $10^{*}$ passage pour la souche DKI.

- Les milieux et les procédés de culture varient aussi.

On utilise, selon les instituts producteurs, des bouillons au cœur ou au foie de bœuf, des bouillons peptonés ou tryptosés. Le sérum additionnel est soit du sérum de cheval, de zébu, de dromadaire ou de porc.

Malgré les premières affirmations de DUJARDIN-BEAUMETZ, l'influence de l'espèce donatrice de sérum homologue ou hétérologue ne paraît pas jouer un rôle important, pour 
autant que le sérum soit dépourvu d'anticorps inhibant la croissance.

Le $\mathrm{pH}$ de départ est ordinairement élevé, voisin de 8 , mais le pouvoir tampon des milieux varie énormément : certains ajoutent de puissants tampons, d'autres omettent le glucose générateur d'acidité car un $\mathrm{pH}$ final trop bas constitue un mauvais facteur de conservation de vaccin. Enfin, la culture est soit statique, soit sous agitation rotative, soit sous aération forcée.

Le nombre des repiquages demeure aussi très variable, car il doit tenir compte du pouvoir pathogène naturel de la souche originelle, de la fréquence des repiquages, du milieu utilisé et surtout de la réceptivité du bétail local à l'inoculation préventive. Tel vaccin utilisable ici ne pourra l'être ailleurs, notion tôt reconnue par les expérimentateurs, mais qui, perdue de vue sur le terrain, a été génératrice de graves mécomptes dus aux mortalités postvaccinales. Il paraît donc, non seulement impossible de fixer les limites strictes aux repiquages de telle souche, mais encore imprudent de vouloir transposer, sans essais précis dans une région, les méthodes reconnues favorables ailleurs.

C'est là vraisemblablement que réside la cause principale du discrédit jeté sur ce type de vaccins accusés de déclencher d'imprévisibles accidents de vaccination pour des souches pervenues à un nombre donné de passages, alors que les passages antérieurs s'étaient révélés parfaitement inoffensifs. En effet, un facteur fondamental avait été négligé : l'hyperréceptivité évolutive «à éclipse » de certains groupes de bovins, dont le laboratoire ne saurait être tenu pour responsable, mais dont le planificateur d'une campagne vaccinale doit tenir compte.

- Les possibilités de lyophilisation n'ont, dans le passé, guère été appliquées à ce type de vaccin. Après des premiers essais encourageants avec la souche $V_{5}$, les recherches de PRIESTLEY et de ses collaborateurs avaient montré que les cultures lyophilisées de $M . m y$ coides vaccinaient mal, à moins que n'y soient adjoints des adjuvants de l'immunisation (solution gélosée à 0,5 p. 100 préparée extemporanément, huiles minérales) $(10,64,66)$. Or, les progrès enregistrés sur les supports de lyophilisation ont révélé le faible intérêt des immunoadjuvants par rapport au nombre de germes vivants, souvent trop faible dans les procédés antérieurs de conservation.

- Les techniques d'inoculation diffèrent selon les instituts, les souches, les pays. En règle générale, la vaccination intradermique à l'extrémité caudale est pratiquée avec les souches les plus pathogènes, mais aussi avec la souche $T_{1}$ atténuée, du moins dans l'Est africain et en Nigéria.

La voie sous-cutanée rétroscapulaire a la faveur des vaccinateurs en Afrique occidentale, en Ethiopie et au Soudan, et aussi en Zambie avec la souche $T_{1}$ du Kenya.

Les suites de l'inoculation sont variables et se résument normalement en une tuméfaction au point d'inoculation, apparaissant dans les 10 jours et rétrocédant en une semaine. Toutefois, un œdème extensif est toujours à redouter et sa fréquence imprévisible. Les accidents postvaccinaux sont désormais justiciables d'un traitement antibiotique par la tylosine ou la spiramycine (45), mais cette opération reste difficilement applicable en prophylaxie de masse dans les conditions africaines.

Avec ce type de vaccin, il semble qu'une réaction locale soit vraiment nécessaire pour entraîner l'immunité; inversement, l'absence de réaction vaccinale, si minime soit-elle, doit faire redouter l'inefficacité d'un vaccin mal conservé ou mal inoculé (53).

Par crainte de réactions locales trop violentes, on a préconisé l'injection de cultures très atténuées, suivies, à 4 ou 6 semaines d'intervalle, de vaccins plus pathogènes, voire d'une troisième intervention comme au Kenya en 1921-25 puis en 1961-62 au Nigéria et au Tanganyika en 1944. Mais la méthode est alors inapplicable en élevage extensif : aussi a-t-elle été abandonnée après un dernier essai dans le Masaïland de Tanzanie en 1963.

A la suite d'une mycoplasménie précoce et transitoire, la conversion sérologique porte sur les anticorps agglutinants, précipitant et fixant le complément, dont le taux s'élève en quelques jours et se maintient pendant 6 à 7 semaines, semblable à celui rencontré chez les malades $(1 / 20$ à $1 / 80)(16,82)$; chez certains, la positivité persiste pendant plusieurs mois, mais de nombreux animaux vaccinés n'accusent aucune réponse sérologique. 
L'immunité, d'installation assez lente, réclame 2 à 6 semaines pour se parfaire, avec un rapport entre le pouvoir pathogène résiduel des souches et la précocité et le degré d'immunité obtenue.

L'efficacité de la vaccination est acceptable, sans pour autant être excellente. Sans partager le pessimisme de PRIESTLEY (*), il faut bien reconnaître que les dizaines de millions de doses de vaccin employées en Afrique pendant plus de trente ans, des années 1930 à 1960 , n'ont que peu modifié l'épizootiologie de la maladie. Défaillance du vaccin, erreurs dans les programmes, qui négligeaient les vaccinations de masse pour n'entreprendre que des actions locales, difficultés dans leur réalisation dues à l'homme ou à la maladie: il est bien difficile de faire la part de ces divers facteurs. Cet échec prophylactique devait être reconnu aux premières journées panafricaines de Zootechnie en 1954 et conduire, trois ans plus tard, à une réunion organisée à Khartoum par la F.A.O., l'O.I.E. et l'I.B.A.H., pour définir l'orientation des recherches nouvelles, d'où sont sortis les vaccins modernes (74 à 78).

La pratique actuelle de ce type de vaccination s'adresse à la souche $T_{1}$, qui a surclassé les autres, moins par suite de ses qualités propres qu'en raison de la lassitude des expérimentateurs à rechercher des souches inédites. Officiellement consacrée, c'est sur elle que se fonde la campagne de vaccination interafricaine $(4,13,15,16,19,23,52,85)$.

En réalité, elle ne paraît cependant ni meilleure ni pire qu'une autre et son succès principal dérive des progrès réalisés dans la technologie de sa production, principalement dans la constitution d'une banque lyophilisée au $44^{\mathrm{e}}$ passage en œuf embryonné, permettant d'obtenir un produit toujours semblable à lui-même.

Les techniques de production sont parfaitement codifiées $(4,13)$. Dans les pays africains anglophones, le vaccin est délivré sous forme liquide par les Iaboratoires, imposant l'impérieuse nécessité d'une chaîne de froid ininterrompue $(4,52)$. Dans les pays francophones et en Ethiopie, le vaccin $T_{1}$ est lyophilisé (19). Les valeurs immunigènes de l'un et l'autre produits sont égales pour autant que la dose vacci-

(*)"... Although production and use of this vaccine have steadly increased..., there is little evidence of a decreasing incidence of the disease." nale contienne au moins $10^{7}$ germes revivifiables après Iyophilisation (24). Les réserves de certains à l'égard du vaccin lyophilisé (39) ne trouvent de fondement que dans la méconnaissance de tours de main de production; pour être pleinement valable et préserver au maximum la viabilité du produit lyophilisé, la dessiccation doit être conduite à très basses températures, ce qui n'est possible qu'avec certains types de lyophilisateurs; en d'autres termes, la différence d'opinion n'a d'autre support que des différences dans le matériel de laboratoire.

Selon les régions où la souche $T_{1}$ est utilisée, la voie d'introduction sous-cutanée peut conduire à de très violents accidents chez les taurins, où elle est contre-indiquée (44), mais la règle veut que, même chez les zébus, quelques individus développent de fortes réactions vaccinales; aussi certains laboratoires préconisent-ils toujours l'inoculation intracaudale. Utilisée sur le terrain pendant 4 ans en Ouganda, elle a rendu d'immenses services, sans pour autant annuler les pertes, en dépit d'une durée d'immunité solide étalée sur au moins 1 an $(52,85)$.

Une autre souche d'ovoculture, la souche $T_{2}$ de SHERIFF et PIERCY primitivement délivrée comme ovo-vaccin (voir plus bas), est, au laboratoire de Farcha, cultivée depuis plusieurs années en milieu liquide puis lyophilisée. Elle constitue un vaccin de tout premier ordre quant à ses qualités immunigènes, mais requiert un mode d'inoculation particulier (voie du mufle) qui entrave sa vulgarisation à grande échelle. Actuellement, elle est réservée à l'intervention dans les foyers de péripneumonie où elle fait disparaître les cas cliniques en moins de deux semaines, laissant un troupeau solidement immunisé.

\section{c) Atténuation artificielle in ovo}

Tombés en désuétude par suite d'accidents d'inoculations, les vaccins antipéripneumoniques d'ovoculture ont connu en leur temps leur heure de gloire. Ils réclament une adaptation initiale à l'œuf; les passages successifs amoindrissent, pour certaines souches, le pouvoir pathogène vis-à-vis du bœuf, ainsi qu'une dégradation de leur aptitude immunogène comme pour les cultures en bouillon (80).

Les souches utilisées furent, en particulier, la souche $T_{1}$ de SHERIFF et PIERCY (80), 
utilisée du $35^{\mathrm{e}}$ au $41^{\mathrm{e}}$ passage, la souche $T_{3}$ des mêmes auteurs, du $11^{\mathrm{e}}$ au $20^{\mathrm{e}}$ passage. Leur pouvoir pathogène varie, la plus atténuée étant la souche $T_{1}$, la plus pathogène la souche $T_{3}$ $(41,59,60,61)$.

Des divergences inattendues du pouvoir pathogène risquent de se produire d'un passage à l'autre ou, pour un même passage, d'un lot de bovins vaccinés à un autre. Les vaccins d'ovoculture ont connu cependant un authentique succès, en raison de la facilité de leur lyophilisation et de la possibilité de préparation de produits stables contrastant avec les déboires obtenus à cette époque (1955-1960) avec les cultures en bouillon. Ce sont d'ailleurs leurs heureuses qualités de conservation qui ont imposé leur choix pour la préparation des cultures de départ des vaccins en bouillon.

Le procédé général de production s'adresse à des œufs de 7 jours d'incubation, inoculés par voie intravitelline. Après réincubation à $35^{\circ} \mathrm{C}$, on récolte la totalité des œufs morts du $3^{\mathrm{e}}$ au $7^{\mathrm{e}}$ jours après l'inoculation; puis interviennent l'homogénéisation et la lyophilisation, avec ou sans addition de diluants protecteurs $(60,69)$.

La dose minimale immunisante oscille autour de 20.000 « unités revivifiables », taux très inférieur à celui des cultures en bouillon. On admet, avec PRIESTLEY, que la facilité d'implantation des souches d'ovoculture tient à l'action adjuvante in situ du matériel venant de l'œuf (63).

La lyophilisation simplifie considérablement la conservation, car ces vaccins sont stables plusieurs années à $-20^{\circ} \mathrm{C}$, plusieurs mois à $4^{\circ} \mathrm{C}$, plusieurs semaines aux températures extrêmes des tropiques à la condition qu'ils soient maintenus à l'obscurité $(35,36)$.

Les procédés d'inoculation diffèrent selon la pathogénicité des souches et la réceptivité du bétail suivant les régions :

- soit l'inoculation sous-cutanée en arrière de l'épaule avec la souche $\mathrm{T}_{1}$ atténuée;

- soit l'inoculation sous-cutanée à l'extrémité caudale avec la souche $T_{3}$, plus virulente. Au Kenya, la double vaccination avec la souche $T_{1}$, puis avec la souche $T_{3}$ a été abandonnée, par suite de chocs anaphylactiques survenus sur 3 p. 100 des vaccinés;
- soit le procédé de Farcha (69), d'inoculation profonde dans le mufle (schéma). Le lieu d'inoculation est représenté par le point d'intersection de la ligne médiane du mufle et de celle joignant le bord inférieur des naseaux. L'aiguille est implantée perpendiculairement à la peau et enfoncée sur une profondeur de 1 à $1,5 \mathrm{~cm}$. Strictement respecté, le procédé se montre inoffensif, comme l'a confirmé BROWN (3), même pour des souches hautement pathogènes : les taurins des races N'Dama et Baoulé existant en République centrafricaine ne se montrent pas plus sensibles à l'inoculation que les zébus Choas ou Bororos; toutefois, si l'inoculation intervient en position supérieure, se manifeste alors un cedème inflammatoire s'étendant à toute la tête, entraînant parfois la mort;

- soit le procédé de Dakar, d'inoculation strictement intradermique à l'oreille $(55,56)$, sur la face supérieure du pavillon auriculaire; il se fonde sur l'extraordinaire capacité de résorption du derme local.

Les suites vaccinales existent ou non suivant la souche et le mode d'inoculation. Ainsi, la souche $T_{1}$ est bien tolérée par voie souscutanée, mais les souches $T_{2}$ et $T_{3}$ y déclenchent des réactions locales violentes et doivent être insérées par les autres méthodes. La voie intradermique paraît être remarquablement tolérée, mais les inoculations doivent être particulièrement soignées.

Quels que soient le vaccin d'ovoculture et le procédé de vaccination, peuvent, là encore, se produire des accidents imprévisibles: par voie sous-cutanée ou caudale, ce sont des cedèmes envahissants; par voie du mufle, une infiltration des tissus de la tête pouvant conduire à des «faces d'hippopotames (photo $\mathrm{n}^{\circ} 3$ ); par voie intradermique à l'oreille, de volumineuses adénites préparotidiennes pouvant se fistuliser. Ces accidents se traitent avec le novarsénobenzol ou un antibiotique majeur (tétracycline, tylosine, spiramycine). Il semble que les taurins d'Afrique occidentale y soient plus volontiers exposés que les zébus, et réclament l'inoculation intradermique.

Quelques jours après la vaccination, une toux légère et fugace, peut-être d'origine allergique, a été assez fréquemment signalée (69).

Plus sévères apparaissent les accidents pulmonaires postvaccinaux, signalés tout d'abord 


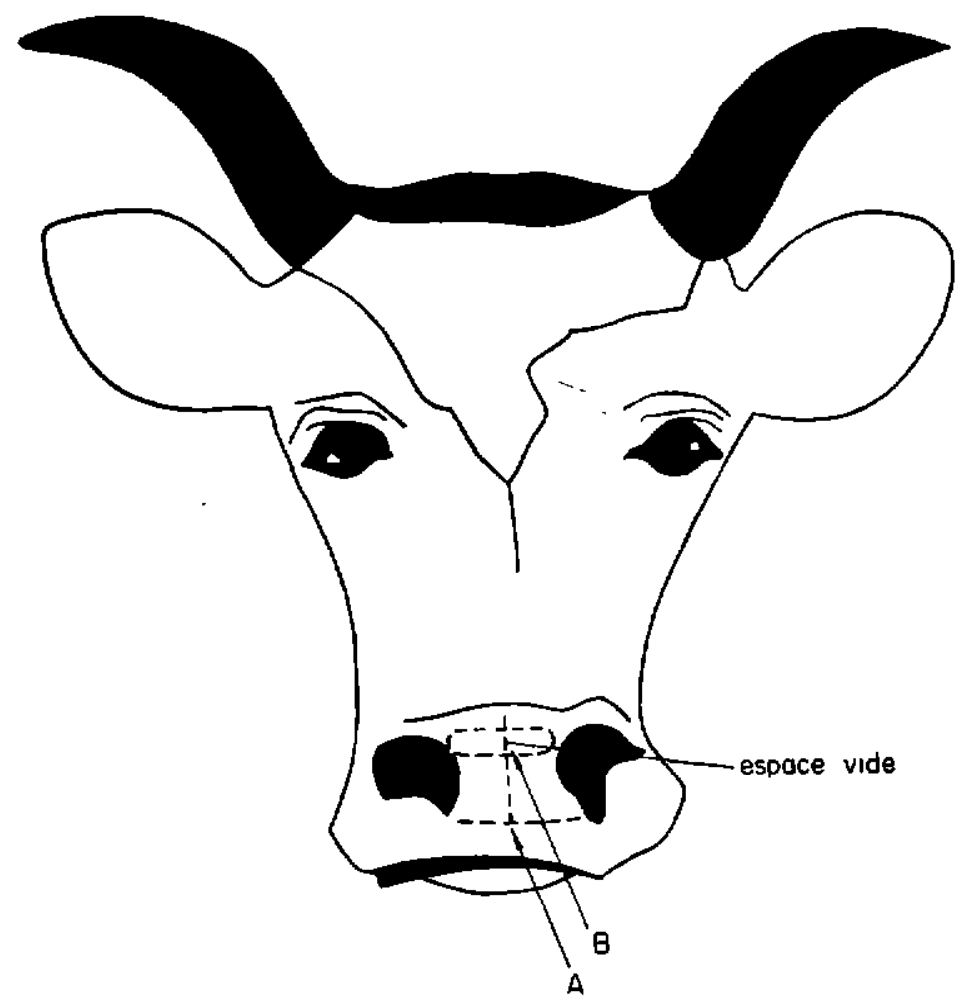

Schéma: Lieu d'élection de la vaccination antipéripneumonique avec les souches atténuées par ovoculture.

Le vaccin doit être inoculé en $A$, site "permis» à conjonctif dense peu réactionnel, et non en $\mathrm{B}$, site « interdit », à conjonctif lâche, très réactionnel.

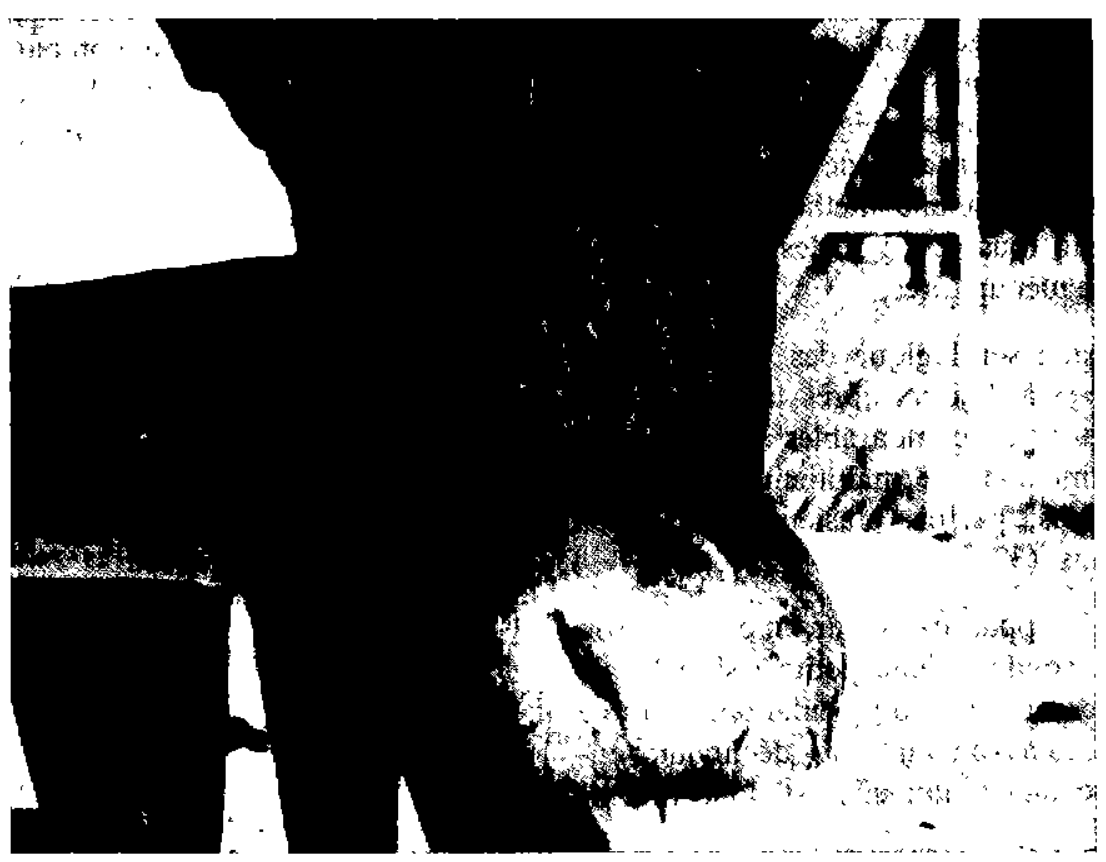

Photo 3. - Réaction postvaccinale.

Après vaccination au mufle, phénomène de Willems local en * face d'hippopotame ». 
dans l'Est africain, avec lésions pulmonaires de péripneumonie transmissible par contact. Expérimentalement, ces accidents ont été reproduits en Australie sur les vaches laitières avec un vaccin d'ovoculture de la souche $V_{5}(33)$. Leur étiologie n'est pas entièrement élucidée, mais le pouvoir pathogène résiduel propre de la souche parait y entrer pour une grande part, puisque la souche totalement apathogène $\mathrm{KH}_{3} \mathrm{~J}$, mélangée aux liquides embryonnaires, n'en a jamais été accusée; d'autre part, ils n'apparaissent qu'à la suite de réactions locales extensives. Mais un autre facteur semble résider dans les liquides embryonnaires eux-mêmes, car les mêmes souches $V_{5}$ ou $T_{3}$ en bouillon se montrent incapables d'induire de tels accidents (29).

Néanmoins, les vaccins des souches $T_{2}$, cette dernière désormais cultivée en bouillon comme on l'a dit plus haut, et $\mathrm{T}_{3}$ continuent à être utilisés, respectivement dans le Centre et l'Ouest africain, où ils sont remarquablement tolérés par le bétail; inoculé par erreur dans le mufle sur 8.000 bovins vivant en région vierge d'enzootie péripneumonique, le vaccin de la souche $T_{2}$ ne s'est révélé aucunement pathogène. A l'inverse, la vaccination répétée du bétail Masaï de Tanzanie avec le vaccin d'ovoculture, entre les années 1955 et 1958 n'a conduit qu'à une augmentation du nombre de foyers.

En outre, dans les foyers de péripneumonie en activité, on constate, dans les quelques jours suivant la vaccination, une exacerbation de la mortalité due à des accès aigus de la maladie. II est pourtant déconseillé de pouvoir établir sur cette observation une méthode de «stamping-out $»$, car tous les malades ne sont pas touchés, à beaucoup près.

La conversion sérologique des bovins vaccinés s'observe 3 à 4 jours après la vaccination au mufle et les titres, comparables à ceux observés chez les malades, se maintiennent pendant 6 à 8 semaines, parfois plusieurs mois chez certains bovins (37).

L'immunité apparaît en un mois environ d'autant plus solide qu'une petite lésion locale s'est produite au point d'inoculation, durable pendant au moins un an, puis déclinante ensuite : la vaccination annuelle est donc recommandée.

$\mathrm{Au}$ total, requérant des techniques d'inoculations particulières et souvent accusées, à bon escient, d'accidents importants, il est douteux que les vaccins d'ovoculture aient encore devant eux un brillant avenir. Mais dans l'histoire des vaccins antipéripneumoniques ils auront eu au moins le mérite d'introduire la pratique féconde de la lyophilisation.

\section{d) Souche murinisée}

«La murinisation » de $M$. mycoides, par adaptation à la souris, a été étudiée en Angola, mais n'a pas dépassé le stade expérimental (22).

\section{e) Souche atténuée en cultures de tissu}

La souche australienne Gladysdale, hautement pathogène à l'origine puisqu'elle est la souche standard des épreuves d'immunité par contact (34), a été atténuée par KARST et MITCHELL (40) par 20 passages en cultures cellulaires de rein de veau. Elle se montre alors atténuée, ne déclenchant aucune réaction willemsienne par inoculation sous-cutanée, et stable dans son atténuation puisque 10 passages de retour en série chez le bouf ne lui font pas recouvrer sa virulence initiale.

L'originalité du travail de KARST et MITCHELL réside en plus dans le mode d'application du vaccin lyophilisé préparé avec cette souche, qui fait appel à l'épandage du produit sur la muqueuse pituitaire (vaccination nasale), entraînant une immunité comparable, 6 mois après la vaccination, à celle de la souche $T_{1}$. La protection est déjà valable au bout de 24 heures après l'application vaccinale.

Cette voie d'introduction, explorée pour la peste bovine par PROVOST et BORREDON (68 a), se révèle donc extrêmement prometteuse pour la péripneumonie et mérite que les recherches soient poursuivies à son sujet, pour voir si son utilisation est possible sur le terrain notamment dans les foyers de la maladie.

\section{Souches totalement avirulentes}

Trente années d'utilisation des souches semivirulentes avaient fait oublier les opinions de KNOWLES et de BENNETT (1) qui affirmaient qu'aucune réaction locale postvaccinale n'est nécessaire pour autant que la souche soit bien choisie et l'inoculation non traumatisante. C'est ce que tendent à montrer les expériences puis l'utilisation à plus ou moins 
grande échelle d'une souche particulière, appelée $\mathrm{KH}_{3} \mathrm{~J}$, dénuée de tout pouvoir pathogène.

L'historique de la souche est obscur : originaire de Juba au Soudan, elle a été entretenue au laboratoire de Khartoum par de nombreux repiquages et fut, en 1948, importée au laboratoire de Vom en Nigéria, en même temps que d'autres souches soudanaises. Là, elle y a été soigneusement étudiée par GAMBLES, puis LINDLEY, avant d'être utilisée sur le continent australien, où HUDSON a confirmé sa valeur et son innocuité. La variante australienne de la souche a subi 4 passages in vivo dans l'organisme bovin et représente la $90^{\circ}$ subculture $(21,30,42)$.

La souche $\mathrm{KH}_{3} \mathrm{~J}$ présente des caractéristiques de culture particulières : sa cuiture en bouillon est du type $S$, non filamenteuse et sur gélose, elle donne naissance à deux types de colonies de $M$. mycoides, cernées par une zone périphérique moins étendue et plus claire. Instables, ces deux types coloniaux sont indifféremment et réciproquement reconvertibles et offrent une valeur antigénique identique.

La culture de la souche $\mathrm{KH}_{3} \mathrm{~J}$ est classique et son immunogénèse se place sous la dépendance de sa richesse en * unités viables $»$ : aussi doit-on s'efforcer d'obtenir les cultures les plus riches et de conservation la plus longue, d'où la pratique d'abaisser le taux de glucose dans un milieu largement tamponné, et d'y apporter les métabolites indispensables : glycérol, acides palmitique et stéarique (17).

L'ovoculture de la souche, certes réalisable, a enregistré peu de succès car, curieusement, il semble que le produit lyophilisé soit instable et ne conserve que quelques semaines ses propriétés antigéniques.

La conservation du vaccin, sous forme de liquide, est précaire en climat tropical et il est recommandé d'utiliser les préparations dans les 5 jours. En revanche, la lyophilisation du vaccin est aisée, soit en tampon de FRY et GREAVES, avec ou sans concentration des germes par centrifugation, soit, comme à Farcha, en tampon à la casitone et au glutamate de sodium (69). En Australie, on préfère mélanger 1 partie d'une culture de 5 jours à 4 parties des liquides embryonnaires d'œufs de poules incubés depuis 11 jours, ou bien additionner une suspension à 20 p. 100 d'encéphale de bœuf en tampon saccharose-phosphate, formules encore à l'essai et certainement perfectibles $(30,31)$.

Une dose minimale de $10^{7}$ « unités revivifiables » est requise pour l'acquisition d'une immunité correcte, mais un vaccin plus riche serait sans doute préférable $(11,43,46,47)$.

Enfin, différents adjuvants encore à l'étude, ont été essayés : gélose à 1 p. 100 additionnée de supercel à 2 p. 100, broyat d'encéphale de bœuf, $\boldsymbol{B}$. abortus S 19, B.G.G. Cette ligne de recherche est digne d'intérêt car elle peut se montrer capable de redonner un regain de confiance en une préparation qui, on le verra plus loin, possède de solides défauts.

L'injection vaccinale peut s'opérer, en tous points du corps par voie sous-cutanée. Aucune réaction locale ne s'ensuit, même avec des qualités très importantes de culture, de l'ordre de plusieurs litres; il n'y a plus d'accidents pulmonaires, même après mélange du vaccin aux liquides embryonnaires d'œufs (29).

La conversion sérologique des bovins vaccinés n'est ni précoce, ni constante, ni élevée, ni prolongée.

L'immunité apparaît lentement et ne couvre d'ailleurs pas tous les bovins, dans les conditions expérimentales comme dans la pratique; néanmoins, plus de 80 p. 100 des vaccinés sont cliniquement protégés et les auteurs australiens considèrent que la souche $\mathrm{KH}_{3} \mathrm{~J}$ est aussi immunigène que la souche $V_{5}(30)$. Limmunité conférée par la vaccination à la queue paraît du reste très largement supérieure à celle qui suit l'inoculation sous-cutanée rétroscapulaire.

La qualité de l'immunité est en relation avec le nombre de germes revivifiables inoculés, au titre seuil minimal immunisant de $10^{\top}$.

Par ailleurs, la résistance conférée n'est pas totale, puisque $1 / 5$ des bovins vaccinés puis éprouvés par contact 5 mois après vaccination, présentent à l'autopsie des lésions actives ou encapsulées : ce résultat contraste avec celui de l'épreuve par voie sous-cutanée au terme de laquelle 97 p. 100 des bovins sont résistants 1 an après la vaccination $(18,42)$.

Au total, la souche $\mathbf{K H}_{3} \mathrm{~J}$ ne prétend pas primer les autres vaccins antipéripneumoniques. Mais, totalement apathogène et suffisamment immunigène, son utilisation pratique large, comme en Nigéria et au Tchad, a pourtant 
fourni d'excellents résultats, puisque, au Tchad en particulier, la moyenne annuelle des foyers de péripneumonie est tombée de 200 à une dizaine, sous l'influence de cette vaccination systématique. Dans ce dernier pays, la pratique de la vaccination antipéripneumonique, généralement repoussée par les éleveurs, a été facilitée par l'utilisation d'un vaccin mixte antibovipestique-antipéripneumonique, inoculable en un seul temps et fort bien accepté (69).

\section{CHOIX D'UNE METHODE DE VACCINATION}

La multiplicité des formules vaccinales proposées est le plus sûr garant de l'inexistence actuelle d'un vaccin antipéripneumonique idéal.

Diversement nocifs d'une part, diversement actifs au laboratoire d'autre part, les vaccins spécifiques se montrent également d'une efficacité fort diverse sur le terrain, allant d'une excellente immunité totale à la simple résistance clinique accompagnée de séquestres pulmonaires, sources contagifères encore augmentées par la création artificielle de bovins semi-résistants devenant après contamination, porteurs et excréteurs chroniques pérennisant le contage; cette observation est particulièrement vraie avec la souche $\mathrm{KH}_{3} \mathrm{~J}$, mais on la retrouve aussi avec la souche $T_{1}$.

La politique vaccinale se révèle malaisée à définir et éminemment variable selon les circonstances.

En période épizootique, ou pour juguler la maladie dans un troupeau où l'abattage est impraticable pour les raisons que l'on a citées plus haut, le choix portera:

- éventuellement sur l'inoculation willemsienne, opérée par les propriétaires eux-mêmes, qui toléreront les pertes postvaccinales plus aisément que si elles étaient consécutives aux interventions des techniciens. Sous réserve de la propreté contrôlée des opérations et éventuellement d'une antibiothérapie destinée à arrêter les violentes réactions qui pourraient se manifester, elle sera pratiquée soit à la queue, selon la technique originale de WILLEMS à l'aide d'une aiguille infectée de «lymphe», soit au mufle avec une bague à pointes;
- plus logiquement sur les vaccins de cultures en bouillon, dérivés des souches d'ovoculture $\left(\mathrm{T}_{2}\right)$, dont on est en droit d'espérer une genèse immunitaire rapide. L'injection au mufle vaccine très rapidement, en quelques jours, mąis peut entraîner des accidents locaux alarmants et surtout une flambée postvaccinale de mortalité;

- peut-être, dans l'avenir, sur la vaccination par voie nasale, si les espoirs que l'on fonde sont justifiés par l'expérience.

Dans une campagne de vaccination systématique, en période calme, le choix devient délicat car il doit considérer :

- la réceptivité locale du bétail aux différents vaccins utilisables; aussi importe-t-il de ne jamais amorcer une vaccination généralisée sans essais régionaux préalables;

- les circonstances locales, concernant la menace de la maladie pour le noyau d'élevage à protéger, donc la nécessité d'une installation rapide de l'immunité;

- l'attitude des propriétaires devant les réactions postvaccinales et éventuellement la mortalité.

Dès lors, aucune recommandation n'est possible et c'est au vétérinaire organisateur d'opérer un choix judicieux après soigneuse enquête et mûre réflexion.

Compte tenu de ces restrictions, un accord général s'est fait pour l'utilisation de la souche $T_{1}$ dans une campagne interafricaine contre la péripneumonie patronnée par l'Organisation de l'Unité Africaine (projet $\mathrm{n}^{\circ} 28$ de l'OUASTRC). Son innocuité pour l'immense majorité des zébus d'Afrique et ses qualités immunigènes l'ont fait surclasser la souche $\mathrm{KH}_{3} \mathrm{~J}$, pourtant totalement apathogène, mais accusée de ne créer qu'une immunité de trop faible durée et de favoriser la création de porteurs de lésions encapsulées, lors de recontaminations occultes en période d'immunité évanescente. Pour les populations bovines de taurins sans bosse d'Afrique occidentale, particulièrement réceptifs à la péripneumonie et injusticiables de la souche $T_{1}$, trop virulente pour eux, la souche $\mathrm{KH}_{3} \mathrm{~J}$ reste pourtant indiquée en attendant que des recherches aient dégagé un nouveau procédé de vaccination. 


\section{SUMMARY}

Prophylaxis and vaccination in contagious bovine pleuropnenmonis. Evolution of technics and present applications in practice

After showing that at the present time vaccination is the only pragmatically useful method of control in Africa and after indicating the limiting factors of activity of CBPP vaccines, the author reviews the different recommanded vaccines. It is concluded that in the absence of an ideal vaccine which in fact reflects our misappreciation of the immunity in the disease, vaccination has to rely on the $T_{1}$ strain (or eventually on the $\mathrm{KH}_{3} \mathrm{~J}$ strain) for mass prophylaxis and on the $\mathrm{T}_{2}$ strain for outbreak control.

\section{RESUMEN}

Profilaxis y vacunación en la perineumonia bovina. Evolución de las técnicas y aplicaciones prácticas actuales.

El autor muestra que actualmente la profilaxis medical de la perineumonia es el solo método de lucha pragmáticamente válida en Africa c indica los factores limitando la actividad de las vacunas contra la perineumonia. Luego, pasa en revista los varios inmunigenos preconizados. Concluye que, sin vacuna ideal, lo que refleja en realidad nuestro desconocimiento de la inmunidad en la enfermedad, la vacunación ha de utilizar la cepa $T_{1}$, o eventualmente la cepa $\mathrm{KH}_{3} \mathrm{~J}$, para la profilaxis en gran escala, y la cepa $T_{2}$ para la intervención en los focos.

\section{BIBLIOGRAPHIE}

1. BENNETT (S. C. J.). Contagious bovine pleuropneumonia. Culture vaccines. Proc. Pan.-Afr. Agric. Vet. Conf. Pretoria (paper no 13), 1929, 1 : 118-123.

2. BROWN (R.D.). A note an inactivated contagious pleuropneumonia vaccines. Bull. epiz. Dis. Afr., 1966, $14:$ : 281-283.

3. BROWN (R.D.). The Somaliland $S_{1}$ strain of Mycoplasma mycoides. Bull. epiz. Dis. Afr., 1966, 14: 383-390.

4. BROWN (R. D.), GOURLAY (R. N.) et Mac LEOD (A.K.). The production of $\mathbf{T}_{1}$ broth culture contagious bovine pleuropneumonia vaccine. Bull. epiz. Dis, Afr., 1965, 13 : 145-155.

5. CAMPBELL (A.D.). A preliminary note on the experimental reproduction of bovine pleuropneumonia. Bull. Coun. Sci. Ind. Res. Aust., 1938, 11: 103-111.

6. CAMPBELL (A.D.). CBPP. A preliminary note on immunity. J. Coun. Sci. Ind. Res. Aust., 1938, 11: 112-118.

7. Contagious bovine pleuropneumonia now eradicated. Aust. vet. J., 1972, 48 : $\$ 29$.

8. CSIRO. Animal Research Laboratories Annual Report 1963-64. Melbourne, 1964.

9. CURASSON (G.) et HANRAS. Un vaccin contre la péripneumonie bovine. Bull. Acad. vét. Fr., 1930, 3: 95-98.

10. DAFAALLA (E. N.). A preliminary investigation into the adjuvant action of some substances on dried contagious bovine pleuropneumonia organisms. Vet. Rec., 1956, 68 : 393-395.

11. DALEEL (E. E.) et LINDLEY (E. P.). CBPP : a comparison of three culture vaccines. Sud.J.Vet. Sci. Anim. Husb., 1970, 11 : 34-40.

12. DAUBNEY (R.). Contagious bovine pleuropneumonia. Note on experimental reproduction and infection by contact. J. comp. Path., 1935, 48 : 83-96.
13. DAVIES (G.). Growth characteristics of the $T_{1}$ strain of Mycoplasma mycoides. Trop. anim. Hlth Prod., 1969, 1 : 7-12.

14. DAVIES (G.). The persistence of Mycoplasma mycoides in the host after vaccination with $\mathrm{T}_{1}$ broth vaccine. Res. vet. sci., 1969, 10: 225-231.

15. DAVIES (G.) et GILBERT (F.R.). Contagious bovine pleuropneumonia vaccination in East Africa. Bull. epiz. Dis. Afr., 1969, $17: 21-26$.

16. DAVIES (G.), MASIGA (W.N.), SHIFRINE (M.) et READ (W.C.S.). The efficacy of $T_{1}$ strain broth vaccine against contagious bovine pleuropneumonia: preliminary in-contact trials. Vet. Rec., 1968, 83: 239-244.

17. DAVIES (G.), STONE (S. S.) et READ (W. C. S.). Comparative characteristics of various strains of Mycoplasma mycoides. Trop. anim. Hlth Prod., 1969, 1 : 13-18.

18. DOUTRE (M.P.). Valeur de l'immunité conférée par deux vaccins lyophilisés préparés à l'aide des souches $\mathrm{KH}_{s} \mathrm{~J}$ et $\mathrm{T}_{1}$. Bull. O.I.E., 1969, 72: 103129.

19. DOUTRE (M. P.) et CHAMBRON (J.). Valeur de l'immunité conférće par un vaccin antipéripneumonique lyophilisé préparé à l'aide de la souche $T_{1}$. Rev. Elev. Méd. vét. Pays trop., 1970, 23: 163-179.

20. DOUTRE (M. P.), CHAMBRON (J.) et BOURDIN (P.). Valeur de l'immunité conférée par un vaccin mixte antibovipestique-antipéripneumonique lyophilisé préparé à l'aide de la souche $\mathrm{T}_{1}$ (S-R). Rev. Elev. Méd. vét. Pays trop., 1972, 25 : 1-14.

21. GAMBLES (R. M.). Studies on contagious bovine pleuropneumonia with special reference to the complement fixation test. Brit. vet. J., 1956, 112 : $120-127$ et $162-169$. 
22. GERLACH (F.) et HEIKKILA (I.). Immunization of cattle against contagious bovine pleuropneumonia utilizing strains of the infective agent adapted to mice. Bull. epiz. Dis. Afr., 1956, 4 : 193-195.

23. GILBERT (F.R.), DAVIES (G.), READ (W.C.S.) et TURNER (G.R.J.). The efficacy of $T_{3}$ strain broth vaccine against contagious bovine pleuropneumonia : in-contact trials carried out six and twelve months after primary vaccination. Vet. Rec., 1970, 86 : 29-33.

24. GILBERT (F.R.) et WINDSOR (R. S.). The immunizing dose of $\mathrm{T}_{1}$ strain Mycoplasma mycoides against contagious bovine pleuropneumonia. Trop. anim. Hlth Prod., 1971, 3: 71-76.

25. GIRARD (H.). De la vaccination en matière de péripneumonie bovine. Bull. Soc. Path. exot., 1942, 35: 80-87.

26. GRYAZIN (V. I.) et SHCHERBAKOV (I. V.). (Essais de vaccins tissulaires formolés contre la péripneumonie). Tr. Inst. vet. Alma-Ata, 1954, 6: 171-176.

27. HALL (G. N.). Nigeria. Report of the Veterinary Department. 1930.

28. HALL (W. T. K.) et LAWS (L.). Treatment of a severe reaction in a bull resulting from vaccination for contagious bovine pleuropneumonia. Aust. vet. J., 1958, 34 : 189-190.

29. HUDSON (J. R.). Contagious bovine pleuropneumonia : studies in the pathogenesis of lung lesions following vaccination with egg vaccines, Aust. vet. J., 1965, 41 : 36-42.

30. HUDSON (J. R.). Contagious bovine pleuropneumonia : the immunizing value of the attenuated strain $\mathrm{KH}_{3}$ J. Aust. vet. J., 1965, 41: 43-49.

31. HUDSON (J.R.). Contagious bovine pleuropneumonia : development of a satisfactory and safe vaccine. Bull. epiz. Dis. Afr., 1968, 16: 165-172.

32. HUDSON (J.R.). Contagious bovine pleuropneumonia. The keeping qualities of the $V_{5}$ vaccine in Australia. Aust. vet. J., 1968, 44: 123-129.

33. HUDSON (J. R.) et LEAVER (D. D.). Contagious bovine pleuropneumonia : the occurence of lung lesions following vaccination with egg vaccine. Aust. vet. J., 1965, 41: 29-36.

34. HUDSON (J. R.) et TURNER (A. W.). Contagious bovine pleuropneumonia: a comparison of the efficacy of two types of vaccine. Aust. vet. $J ., 1963,39: 373-385$.

35. HYSLOP (N. St. G.). The viability at low temperatures of a dried egg-adapted (Kenya vaccine) strain of Asterococcus mycoides. Vet. Rec., 1955, 67: $411-412$.

36. HYSLOP (N. St. G.). Review on progress on contagious bovine pleuropneumonia in Kenya. Bull. epiz. Dis. Afr., 1955, 3: 266-270.

37. HYSLOP (N.St. G.). Local and serological responses evoked in cattle by strain of Mycoplasma mycoides passaged in embryonated eggs. Bull. O.I.E., 1968, 69, 695-723.

38. KARST (O.). A comparison of 2 vaccines against contagious bovine pleuropneumonia. Res, vet. Sci., 1971, 12, 18-22.

39. KARST (O.). Contagious bovine pleuropneumonia : lyophilised $\left(\mathrm{T}_{1}\right)$ vaccine. Bull, epiz. Dis. Afr. juin 1972, numéro spécial sur la péripneumonie, 69-76.

40. KARST (O.) et MITCHELL (S.). Intranasal vaccination of cattle with an attenuated Gladysdale strain of Mycoplasma mycoides var. mycoides. J. comp. Path., 1972, 82 : 171-178.

41. KNIGHT (G. J.). Studies with ayianised strains of the organism of contagious bovine pleuro- pneumonia. VIII. Experiments with avianised vaccine prepared from Muguga $\mathrm{T}_{2} / 32$ strain of Mycoplasma mycoides. Bull. epiz. Dis. Afr., 1960, 8: 11-19.

42. LINDLEY (E. P.). Experiments with an attenuated culture vaccine against contagious bovine pleuropneumonia. Brit. vet. J., 1965, 121 ; 471478.

43. LINDLEY (E. P.). An immunity test in cattle to compare two contagious bovine pleuropneumonia vaccines. Bull. epiz. Dis. Afr., 1967, 15 : 307-311.

44. LINDLEY (E. P.). Experiences with a lyophilized contagious bovine pleuropneumonia vaccine in the Ivory Coast. Trop. Anim. Hlth Prod., 1971, 3: 33-42.

45. LINDLEY (E. P.). La spiramycine et les lésions postvaccinales au vaccin lyophilisé $M$. mycoides var. mycoides, souche $\mathrm{T}_{1} / 44$ contre la péripneumonie contagieuse des bovidés. Cah. Méd. vét, 1971, 40: 233-236.

46. LINDLEY (E. P.) et ABDULLA (A. E. D.). The development and titration in cattle of a dried contagious bovine pleuropneumonia vaccine. $\mathrm{Su}$ dan I. vet. Sci. anim. Husb., 1967, 8: 40-46.

47. LINDLEY (E. P.) et ABDULLA (A. E. D.). Preliminary test in cattle of some contagious bovine pleuropneumonia vaccines. Sud. J. vet. Sci. Anim. Husb., 1967, 8: 78-87.

48. LINDLEY (E. P.) et PEDERSEN (V.). An experiment on the survival of $M$. mycoides in the tissues of animals vaccinated with contagious bovine pleuropneumonia vaccine. Sud. J. vet. sci. anim. Husb., 1968, 9 : 1-8.

49. MASIGA (W. N.). Achievements of OAU/STRC CP 16 project. Bull. epiz. Dis. Afr. Juin 1972, numéro spécial sur la péripneumonie, 5-11.

50. MENDES (A. M.). Evaluation du vaccin contre la péripneumonie contagieuse des bovidés en Angola. Bull. epiz. Dis. Afr., 1964, 2 : 431-433.

51. METTAM (R. W. M.) et FORD (J.). Experiments on the transmission of bovine contagious pleuropneumonia with a report on a new method of testing immunity following vaccination. $J$. comp. Path., 1939, 52 : 15-28.

52. MINOR ( $\mathbf{R}_{1}$ ). Observations on the use of $\mathbf{T}_{\mathbf{I}}$ broth culture vaccine in the control of contagious bovine pleuropneumonia. Bull. epiz. Dis. Afr., 1967, 15: 115-119.

53. MORNET (P.). La péripneumonie bovine en Afrique occidentale française. Données anciennes et acquisitions récentes. Bull. Serv. zoot, Epiz. A.O.F., 1943, 6: 5-42.

54. ORUE (J.). Prophylaxie de la péripneumonie bovine par le vaccin culture et l'ovo-vaccin dans l'ouest africain francophone. Bilan des dernières campagnes de vaccination. Bull. epiz. Dis. Afr., 1964, 12: 181-186.

55. ORUE (J.) et MEMERY (G.). La péripneumonie bovine. Précisions sur une nouvelle voie d'immunisation. Résultats. Conséquences et hypothèses. Rev. Elev. Méd. vét. Pays trop., 1960, 13: 161173.

56. ORUE (J.) et MEMERY (G.). Note sur la vaccination mtradermique contre la péripneumonie contagieuse bovine. Bull. Acad. vét. Fr., 1960, 33 : $411-418$

57. PALMER (R. F.) et GOURLAY (R. N.). Lyophilisation of Mycoplasma mycoides culture vaccine. Bull. epiz. Dis. Afr., 1964, 12: 397-400.

58. PEARSON (C. W.) et LLOYD (L. C.). Freezedrying of the $\mathrm{KH}_{3} \mathrm{~J}$ vaccine strain of Mycoplasma mycoides. Bull. epiz. Dis. Afr., 1971, 19: 117122 . 
59. PIERCY (S. E.) et KNIGHT (G. J.). Studies with avianised strains of the organism of contagious bovine pleuropneumonia. A further examination of growth and modification in embryonated eggs. Vet. Rec., 1956, $68: 367-373$.

60. PIERCY (S. E.) et KNIGHT (G. J.). Studies with avianised strains of the organism of contagious bovine pleuropneumonia. IV. The preparation, tutration and challenge of avianised bovine pleuropneumonia vaccines. Bull. epiz. Dis. Afr., 1957, 5: 161-173.

61. PIERCY (S. E.) et KNIGHT (G. J.). Studies with the avianised strains of the organism of contagious bovine pleuropneumonia. V. Experiments with avianised vaccines at various levels of attenuation. Brit. vet. J., 1958, 114: 245-253.

62. POTAROFF (A.S.). (Vaccin formolé contre la péripneumonie). Sov. Vet., 1934 (11) : 33-36.

63. PRIESTLEY (F, W.). Contagious bovine pleuropneumonia. Bull. epiz. Dis, Afr., 1955, 3: 126.

64. PRIESTLEY (F.W.). Further observations on immunity to contagious bovine pleuropneumonia with special reference to adjuvants. Vet. Rec., 1955, 65: 729-733.

65. PRIESTLEY (F.W.). Report to the government of Somalia. Rome, F.A.O., 1961. (Rapport F.A.O.ETAP no 1354).

66. PRIESTLEY (F, W.) et DAFAALLA (E. N.). Immunisation against contagious bovine pleuropneumonia using dried organisms and adjuvants. Bull. epiz. Dis, Afr., 1957, 5: 177-186.

67. PROVOST (A.). Rapports annuels du Laboratoire de Farcha pour les années 1964, 1965, 1966.

68. PROVOST (A.). Principes de production dun vaccin mixte associé antibovipestique-antipéripneumonique inoculé en un seul temps. Bull. epiz. Dis. Afr., 1969, 17 : 7-10.

68 a. PROVOST (A.) et BORREDON (C.). Essai de vaccination antibovipestique par voie pernasale de veaux possédant ou non une immunité colostrale. Rev. Elev. Méd. vét. Pays trop., 1972, 25 : 141-153.

69. PROVOST (A.), BORREDON (C.) et QUEVAL (R.). Recherches immunologiques sur la péripneumonie. XI. Un vaccin vivant mixte antibovipestique-antipéripneumonique inoculable en un seul temps. Rev. Elev. Méd. vét. Pays trop., 1970, 23 : 143-162.

70. PROVOST (A.), PERREAU (P.) et QUEVAL (R.). Essais de vaccination antipéripneumonique à l'aide de corps microbiens lysés. Echec. Bull. epiz. Dis. Afr., 1963, 11 : 375-380.

71. PROVOST (A.), VILLEMOT (J. M.) et QUEVAL (R.). Recherches immunologiques sur la péripneumonie. VIII. Immunisation au moyen d'une souche avianisée de Mycoplasma mycoides var. mycoides inoculée par la voie du mufle. Rev. Elev. Méd. vét. Pays trop., 1959, 12 : 381-404.
72. PROVOST (A.), VILLEMOT (J. M.) et QUEVAL (R.). Quatre années de pratique de la vaccination antipéripneumonique en Afrique centrale. Bull. epiz. Dis. Afr, 1962, 10: 433-438.

73. PROVOST (A.), VILLEMOT (J.) et QUEVAL (R.). Essais de vaccination contre la péripneumonie à l'aide de micro-organismes du genre Mycoplasma autres que $M$. mycoides. Bull. epiz. Dis. Afr., 1964, 12 : 153-158.

74. Rapport de la réunion sur la péripneumonie contagieuse des bovins. Rapport de réunion FAO $1957 / 2$.

75. Rapport de la 1re réunion du groupe d'experts FAO/OIE/CCTA sur la péripneumonie bovine. Rapport FAO-AN 1960/3.

76. Rapport de la 2 e réunion du groupe dexperts FAO/OIE/CCTA sur la péripneumonie bovine. Rapport FAO-AN 1964/1.

77. Rapport de la 3e réunion du groupe d'experts FAO/OIE/OUA sur la péripneumonie. Rapport FAO-AN 1967/2.

78. Réunion du sous-comité du groupe d'experts FAO/OIE/OUA sur la péripneumonie bovine. Bull. epiz. Dis. Afr., juin 1972, numéro spécial sur la péripneumonie, 91-100.

79. ROCHEBRUNE (A.T. de). Formation de races nouvelles. Recherches d'ostéologie comparée sur une race de bœufs domestiques observée en Sénégambie. C.R. Acad. Sci., Paris, 1880: 304306.

80. SHERIFF (D.) et PIERCY (S. E.). Experiments with the avianised strain of the organism of contagious bovine pleuropneumonia. Vet. Rec, 1952, 64: 615-621.

81. SHIFRINE (M.) et BEECH (J.). Preliminary studies on living culture and inactivated vaccines against contagious bovine pleuropneumonia. Bull. epiz. Dis. Afr., 1968, 16: 47-52.

82. SHIFRINE (M.), STONE (S. S.) et DAVIES (G.) Contagious bovine pleuropneumonia: serologic response of cattle after single and double vaccination with $\mathrm{T}_{1}$ culture vaccine. Rev. Elev. Méd. vét. Pays trop., 1968, 21 : 49-58.

83. WALKER (J.). Experiments and observations in connection with pleuropneumonia contagiosa bovum and the preventive method of inoculation. Dep. Agr. Kenya, Bull. n० 2, pp. 136-183, East Afr. Stand. Ltd., Nairobi, 1921.

84. WALKER (J.). Ann. Rep. Dept. Agr., Kenya, 1929 , p. 240.

85. WINDSOR (R. S.), MASIGA (W. N.) et READ (W. C. S.). The efficacy of $\mathbf{T}_{1}$ strain broth vaccine against contagious bovine pleuropneumonia. Incontact trials carried out two years after primary vaccination. Vet. Rec., 1972, $90: 2-5$. 